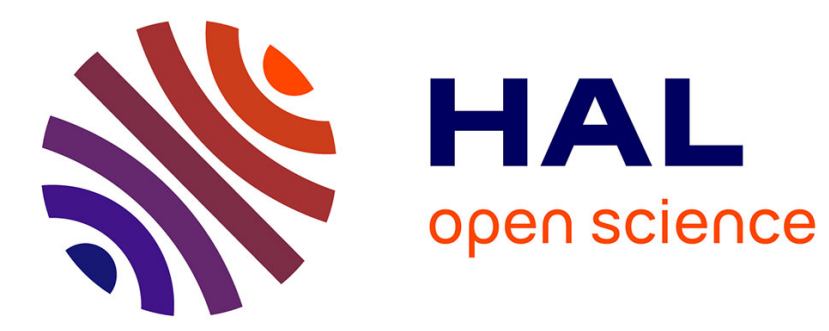

\title{
Development of structural and functional connectivity
}

Jessica Dubois, I Kostovic, M Judas

\section{To cite this version:}

Jessica Dubois, I Kostovic, M Judas. Development of structural and functional connectivity. Brain Mapping: An Encyclopedic Reference, 2, pp.423 - 437, 2015. hal-02436274

\section{HAL Id: hal-02436274 https://hal.science/hal-02436274}

Submitted on 12 Jan 2020

HAL is a multi-disciplinary open access archive for the deposit and dissemination of scientific research documents, whether they are published or not. The documents may come from teaching and research institutions in France or abroad, or from public or private research centers.
L'archive ouverte pluridisciplinaire HAL, est destinée au dépôt et à la diffusion de documents scientifiques de niveau recherche, publiés ou non, émanant des établissements d'enseignement et de recherche français ou étrangers, des laboratoires publics ou privés. 


\title{
Development of structural and functional connectivity
}

\author{
J. Dubois, I. Kostovic and M. Judas
}

\section{Affiliations:}

1: Jessica Dubois, INSERM, U992, Cognitive Neuroimaging Unit, Gif-sur-Yvette, France; CEA, NeuroSpin Center, Gif-sur-Yvette, France; University Paris Sud, Orsay, France

2: Ivica Kostovic and Milos Judas, University of Zagreb School of Medicine, Croatian Institute of Brain Research, Salata 12, 10000 Zagreb, Croatia

Corresponding author:

Jessica Dubois, $\mathrm{PhD}$

CEA/SAC/DSV/I2BM/NeuroSpin/Cognitive Neuroimaging Unit U992

Bât 145, point courrier 156

91191 Gif-sur-Yvette, France

Email: jessica.dubois@centraliens.net

Brain Mapping: An Encyclopedic Reference, 2015. vol. 2, pp. 423-437.

In: Arthur W. Toga, editor. Academic Press: Elsevier.

\section{Synopsis}

In the human brain, development of structural connectivity starts during the early fetal period, and progresses in a complex but sequential way, until all major axonal pathways become established in the preterm period, as outlined by post mortem and in vivo studies based on histological stainings and MRI. Through the myelination process, these networks further mature and refine after term birth until the end of adolescence, leading to the emergence of mature patterns of functional connectivity in the course of development.

\section{Keywords}

Brain development, maturation

White matter pathways

Myelination

Functional organization

Resting-state networks

Structural and functional MRI

Diffusion tensor imaging DTI

Tractography

Preterm newborn, infant

\section{Glossary}

Fiber myelination: brain maturational mechanism corresponding to the ensheatment around neuronal axons of oligodendrocytes' processes that form the myelin sheaths. It leads to an increase in the conduction speed of the nerve impulse, and progresses from the second part of pregnancy to the end of adolescence with a specific calendar across white matter bundles and cerebral regions.

Subplate: transient cerebral compartment containing the most differentiated postmigratory neurons, observed between the intermediate zone (fetal white matter) and the cortical plate between 13 PCW and around term age (still observed in the first postnatal months in some 
frontal association regions). See chapter \#193 for the definitions of other transient fetal zones of the cerebral wall.

\section{Nomenclature}

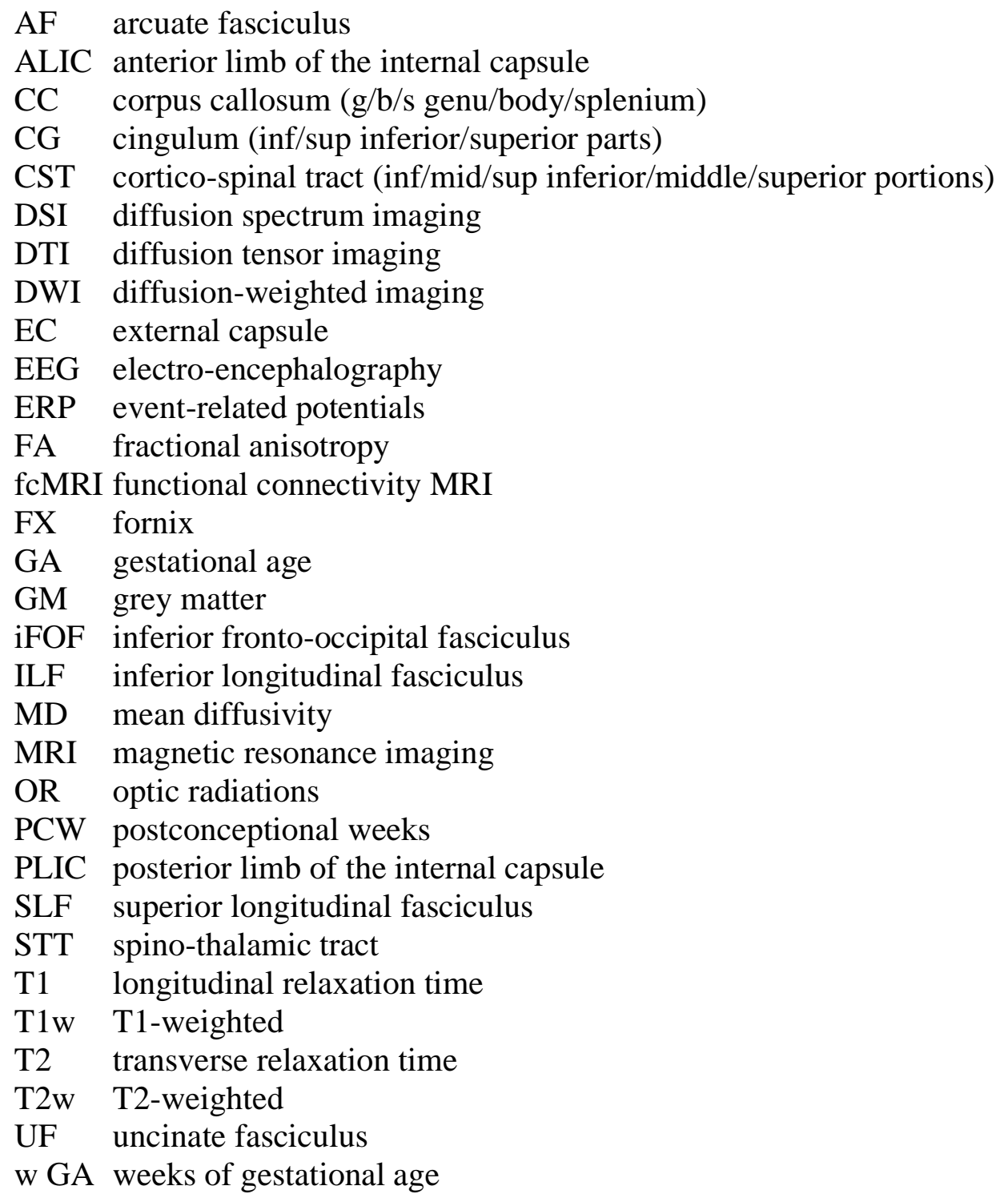




\section{Introduction}

During the early fetal period there are few axonal pathways and synaptic connections already established in the human brain. Thus, starting with this period, we have a unique opportunity to follow step-by-step complex but sequential development of cerebral connectivity, until all major connections become established in the late fetal (preterm) period. Even though the pathways' connectivity and the cortical circuitry (see chapters \#193, 194) are not fully established yet in preterm newborns, brain regions are organised early on into networks specialised to process sensori-motor and cognitive functions (Mahmoudzadeh, et al. 2013). These functional networks further develop, mature and refine until the end of adolescence. In this chapter, we aim to describe the early development of connectivity, from the fetal to the postnatal periods, as mapped in post mortem histological studies and in vivo MRI studies of foetuses, newborns and infants. We successively detail 1) how the structural connectivity first develops, 2) how the white matter pathways then become myelinated and functionally mature, and 3) how functional connectivity emerges in the course of development.

\section{Development of the structural connectivity: fetal and preterm periods}

It is important to note that: 1) transient fetal patterns of cerebral connectivity differ significantly from postnatal connectivity; 2) prenatal development of connectivity is regulated and coordinated through interactions with other histogenetic events, such as proliferation, migration, cell aggregation, molecular specification of neuronal phenotypes, cell death and myelination; 3) two major connectivity networks (extrinsic modulatory and intrinsic local cortical networks) (for reviews (Kostovic and Judas 2006; Kostovic and Judas 2007; Kostovic and Judas 2010)) remain largely unexplored because their structural and functional development cannot be visualized by current imaging methods. While there are many welldescribed phases of connectivity development (Kostovic and Judas 2002; Kostovic and Judas 2006; Kostovic and Judas 2007; Kostovic and Judas 2010; Kostovic and Rakic 1990; MarinPadilla 1978; Meyer, et al. 2000) here we use a simplified division of connectivity formation into a) early fetal (9-15 postconceptional weeks, PCW), b) midfetal (15-23 PCW), c) early preterm (24-28 PCW) and d) late preterm (29-34 PCW) period.

\section{Early fetal period (9-15 PCW)}

During this period, the overall density of connectivity and synaptic contacts is low, and dominant processes are growth and pathfinding of major afferent and efferent pathways within the intermediate zone (fetal white matter) and widespread innervation of target regions by modulatory monoamine and acetylcholine afferent fibres (Figures 1, 5a). While most neurons giving rise to future cortico-cortical connections are not yet generated, there is already a well defined internal capsule (between thalamus and striatum) which contains massive thalamocortical fibres directed towards the lateral cerebral wall as well as growing efferent (motor) corticosubcortical projection pathways. Although thalamocortical fibres radiate towards the cerebral wall, they do not penetrate the cortical plate and do not establish synapses in it (Figure 1). The modulatory monoamine brain-stem afferent fibres are already present above and below the cortical plate (Berger and Alvarez 1994; Berger, et al. 1993; Nobin and Bjorklund 1973; Olson, et al. 1973; Verney 1999; Verney, et al. 2002; Zecevic and Verney 1995). In contrast to neocortical fibre systems, which do not display compact bundles but spread widely in radial direction, there are several limbic bundles (Figures 1, 5a) which can already be easily delineated and identified on histological and MRI/DTI images (Vasung, et al. 2010). These bundles are fornix, stria terminalis and cingulum, which originate from subcortical limbic nuclei (amygdala) and within the medial limbic cortex (hippocampus, gyrus cinguli). The key event between 13 and $15 \mathrm{PCW}$ is the formation of fibre- and synapse-rich fetal subplate zone (Kostovic and Rakic 1990) which occurs by expansion and delamination of the deep cortical 
plate in which afferent fibres are significantly evolved. The subplate also contains the most differentiated postmigratory neurons.

\section{Midfetal period (15-23 PCW)}

This period is characterized by transient lamination of fetal cerebral wall and transient connectivity patterns (Kostovic and Judas 2002; Kostovic and Judas 2006; Kostovic and Judas 2007; Kostovic and Judas 2010; Kostovic, et al. 2002). Thalamocortical and basal forebrain afferent fibres form a plexiform network within the subplate "waiting" compartment and establish numerous transient synapses with subplate neurons (Figure 2). Subplate neurons contain both GABA and glutamate, as well as numerous neuropeptides. They not only serve as cortical "input" targets for ingrowing afferent fibres and "output" sources of early efferent projections, but also form important and already active endogenous cortical circuitry (Kostovic and Judas 2006; Kostovic and Judas 2007; Kostovic and Judas 2010). Moreover, subplate already serves as an associative cortico-cortical system for medial cortex. Namely, in the gyrus cinguli the subplate receives voluminous fibre projection from precingulate area and the anterior cingulate cortex, which connect these areas with intermediate and posterior cingulate areas (Figure 2). Thus, at least the cingulate component of medial network hubs (Hagmann, et al. 2010) should be already developed during the midfetal period. The early development of the cingulum bundle is associated with early synaptogenesis in the cingulate cortex (Bourgeois, et al. 1994; Kostovic and Krmpotic 1976; Rakic, et al. 1994). Major cortical efferent pathways already penetrate their targets in striatum, pons and the spinal cord. The corticostriatal projections display modular pattern (Figures 2,3 ) because they selectively target striatal island and matrix compartments (Goldman-Rakic 1981). The massive cortico-pontine pathway (Figure 5a) can be easily identified on DTI images (Vasung, et al. 2010). On the other hand, the corpus callosum is still growing, but it can be already visualized by modern imaging methods both in vivo and in vitro (Bui, et al. 2006; Dubois, et al. 2013; Judas, et al. 2005; Kasprian, et al. 2008) (Figure 4). There is also a progressive differentiation of fibre systems in well-defined tangentional axon strata within the intermediate zone, especially in fronto- and occipito-polar regions (Judas, et al. 2005; Kostovic and Judas 2010; Kostovic, et al. 2002). Another important feature is development of periventricular crossroads (Judas, et al. 2005), i. e. intersections of growing radial (thalamocortical and corticofugal), transverse (callosal), and sagittal (associative) pathways (Figure 5b).

\section{Early preterm period (24-28 PCW)}

The period after $22 \mathrm{PCW}$ is interesting both biologically and clinically, because the development of brain and its functions may now be monitored in vivo even in extrauterine environment, in the case of prematurely born babies, by combining structural approaches such as MRI, volumetric studies of fibre- and synapse-rich transient compartments of the fetal cerebral wall, and functional approaches such as EEG, near infrared spectroscopy (NIRS) and resting-state fMRI.

The major event in the structural development of connectivity is relocation of thalamocortical and basal forebrain afferent fibres from the subplate into the cortical plate (Figure 2) in central, frontal, temporal and occipital regions (Kostovic 1986; Kostovic and Goldman-Rakic 1983; Kostovic and Rakic 1984; Kostovic and Rakic 1990; KrmpoticNemanic, et al. 1980; Krmpotic-Nemanic, et al. 1983). This leads to initial synaptogenesis within the cortical plate (Kostovic and Rakic 1990; Molliver, et al. 1973) and the establishment of first permanent connectivity with future cortical layer IV neurons (Figures 2,3). These initial thalamocortical connections are crucial for establishment of sensory-expectant cortical functions. For example, peripherally elicited pain stimuli are now conveyed directly to the somatosensory cortical plate and cause activation of its neurons (Slater, et al. 2006). Other types 
of sensory stimulation also elicit cortical evoked potentials (Graziani, et al. 1974; Hrbek, et al. 1973; Novak, et al. 1989) (for review (Kostovic, et al. 1995)). This formation of permanent thalamocortical connectivity occurs while the transient fetal circuitry still exists within the subplate, which is the most voluminous compartment in the early preterm brain (Corbett-Detig, et al. 2011; Kostovic and Judas 2006; Kostovic and Judas 2007; Kostovic and Judas 2010; Kostovic and Vasung 2009; Maas, et al. 2004). This prolonged coexistence of transient and permanent cortical circuitry is a salient feature of the developing human cortical connectome (Kostovic and Judas 2006; Kostovic and Judas 2007).

It should be noted that, in early preterm brain, some other afferent and efferent pathways also establish permanent contact with their target areas. The most notable is an early development of limbic cortico-cortical connections in the cingulate, entorhinal and hippocampal cortex (Figures 2, 5b). The early growth of long and short limbic cortico-cortical connectivity (Hevner and Kinney 1996; Kostovic, et al. 1989; Kostovic, et al. 1993) is in contrast with much later development of such connectivity in the neocortex. These medial components of the human fetal cortical connectome display high density of synaptically coupled connectivity (Figure 3) because short pathways are well developed between the entorhinal and hippocampal cortex already during midfetal period (Hevner and Kinney 1996) and massive cingulum bundle synaptically connects active cingulate cortical areas (Bourgeois, et al. 1994; Kostovic and Krmpotic 1976). In contrast, in the lateral neocortex long corticocortical pathways are still growing and short cortico-cortical connections remain poorly developed (Burkhalter 1993; Hevner 2000). However, three neocortical associative pathways develop early in the fetal brain: 1) periventricular fronto-occipital fascicle (Kostovic, et al. 2014), 2) uncinate fascicle (Takahashi, et al. 2012) and 3) the deep portion of the external capsule which contains basal forebrain projections and some rostro-caudally directed associative projections (Figures 2, 5b).

Efferent corticostriatal projections display a characteristic modular termination in island and matrix compartments of the striatum (Goldman-Rakic 1981), which is more prominent than in the midfetal period, but will significantly change after the birth.

The above described changes in structural development of fetal connectivity may explain the fast maturation of general cortical activity and appearance of behavioural states, such as sleep and wake periods. These maturational shifts are clearly reflected in EEG recordings and readily documented in routine monitoring in intense care units. The most characteristic developmental EEG features are great amplitude (giant) waves and transitions from desynchronized to synchronized pattern (Dreyfuss-Brisac 1979; Kostovic, et al. 1995; Milh, et al. 2007; Vanhatalo, et al. 2005). Unfortunately, there are very few fMRI data on this early preterm period.

\section{Late preterm period (29-34 $\mathrm{PCW})$}

Structural and functional studies revealed that this period is characterized by fast development of connectivity (Figures $3,5 b$ ). The main structural event is simultaneous growth of long associative and commissural pathways and the significant increase in the volume of cerebral white matter (Scott, et al. 2011) with clear delineation of most adult-like white matter segments including the initial formation of gyral white matter (Judas, et al. 2005; Judas, et al. 2010a; Judas, et al. 2010b). However, the transient subplate is still present and serves for ingrowth of short cortico-cortical fibres (Kostovic, et al. 2014). At the functional level, there is fast and progressive spatio-temporal differentiation with decrease of discontinuous EEG activity. There is also an evident resting-state activity. Somatosensory, visual and auditory thalamocortical pathways are synaptically active and transient immature cortical responses are well documented in human premature infants. 
In the late preterm, major projection pathways established connection with their target areas (Figure 3) where increased synaptophysine immunoreactivity indicates progressive synaptogenesis. Thalamocortical system responses to sensory stimulation are enhanced by development of local circuitry GABA and peptidergic interneurons in cortical layer IV. Corticostriatal projections and striatal modular compartments display continuous reorganization, but did not reach adult-like modular pattern.

As there are no reliable immunocytochemical markers for long cortical (glutamatergic) associative and commissural pathways, their growth is at present better visualized by modern diffusion-weighted imaging techniques (DTI or DSI, see chapters \#291, 293, 294). However, the direction of their growth remains unresolved even when using such techniques. The likely origin of these pathways are layer III pyramidal neurons (Schwartz and Goldman-Rakic 1991) which are born relatively late during the midfetal period. In vivo and in vitro DTI/DSI studies thus far have been able to identify the following associative pathways (Figure 5): periventricular fronto-occipital and uncinate fascicles, already from earlier stages (Huang, et al. 2006; Takahashi, et al. 2012; Vasung, et al. 2010), the inferior fronto-occipital fascicle (Huang, et al. 2006), and, close to the term, the superior longitudinal fascicle. In the late preterm infant, the emergent short cortico-cortical associative pathways also develop between central and parietal regions (Takahashi, et al. 2012) and display early myelination (Kostovic and Vasung 2009) which was termed "pre-myelination" (Dubois, et al. 2013) and was noted already in classical neuroanatomical studies (Flechsig 1920; Von Monakow 1905) as well as in modern MRI studies (Counsell, et al. 2002; Huppi, et al. 1998a). The short cortico-cortical fibres display arcuate trajectory but are not identical to U-fibres which connect two adjacent gyri and develop after birth (Kostovic, et al. 2014). In the preterm brain, the presence of all projection pathways and growing cortico-cortical pathways contributes to further segmentation of the white matter (Judas, et al. 2005; Von Monakow 1905): 1) periventricular fibre system with corpus callosum, 2) internal capsule with periventricular crossroad area at its exit, 3) corona radiata and centrum semiovale, and 4) gyral white matter (Judas, et al. 2005; Kostovic, et al. 2014; Vasung, et al. 2010). The subplate remnant remains interposed between the gyral white matter and the developing cortical layer VI (Kostovic, et al. 2014). The formation of the corona radiata marks transformation of fetal fibrearchitectonic stratification in two perinatal radiating arrangements of major projection pathways (Kostovic, et al. 2014; Kostovic, et al. 2002). The post mortem DTI/DSI studies revealed an opposite trend in the development of cortical plate and distal (gyral) white matter segments, that is the dominant radial organization of early and midfetal period gradually disappears towards the age at term (Takahashi, et al. 2012). In conclusion, the development of long cortico-cortical pathways with emerging short cortico-cortical fibres and already well developed limbic bundles makes the late fetal cerebral connectome quite dense and similar to dense connectivity of the newborn brain (Figures 3, 5b).

Besides, cortical synaptogenesis in primates is a prolonged postnatal process that involves overproduction of axons, synapses and dendritic spines and their later elimination in response to environmental influences (Kostovic and Judas 2010; Rakic, et al. 1994). In humans, this process extends into the third decade (Petanjek, et al. 2011). Postnatal synaptogenesis is not restricted to neocortical layers I-VI, but also continues on interstitial white matter neurons which are surviving subplate neurons (Judas, et al. 2010a; Judas, et al. 2010b). Thus, there is a considerable postnatal reorganization of cortico-cortical connectivity (for reviews (Innocenti and Price 2005; Judas 2011)). For example, during the early postnatal period, in both rhesus monkey (LaMantia and Rakic 1990) and human brain (for review Innocenti and Price 2005), there is a huge loss of callosal axons in parallel with the major overproduction of cortical synapses. The postnatal prunning of callosal connections in the rhesus monkey lasts for at least 3 to 4 postnatal months (LaMantia and Rakic 1990). On the basis of available data (Kostovic, 
et al. 2014; Kostovic and Rakic 1990; Petanjek, et al. 2011), this process extends in the human brain throughout the first postnatal year, and possibly even longer.

Aside from the investigation of precise white matter pathways, the wiring pattern of cerebral connections have recently been reinterpreted in the "connectome" framework (see chapters \#23, 212). Already at 30w of gestational age (GA), the networks' architecture demonstrates a smallworld modular organization as in the adult brain (van den Heuvel et al., 2014), and cortical hubs are highly connected to form a "rich club" enabling efficient network communication (Ball et al., 2014). Until 40w GA, the small-world topology further increases (van den Heuvel et al., 2014), and connections between core hubs and the rest of the brain proliferate (Ball et al., 2014). The networks further refine during development, with an increase in global efficiency and integration, and a decrease in functional segregation during the first two post-natal years (Yap et al., 2011) and childhood (Hagmann, et al. 2010). Beside the advantage to have no a-priori on pathways' existence and trajectory, a major limitation of structural network analyses in the developing brain is that diffusion-based tractography is highly sensitive to the degree of fiber myelination: some connections would be artefactually missing in comparison with the adult brain insofar as their low maturation would prevent their full reconstruction between cortical regions.

\section{Maturation of the structural connectivity: late preterm and post-term periods}

Indeed, concurrently and subsequently to the organization of white matter networks, connections become progressively mature and functionally efficient through fibres' myelination (Baumann and Pham-Dinh 2001; Van der Knaap and Valk 1995a; Van der Knaap and Valk 1995b; Volpe 2008). This slow process begins after the process of axonal overproductionpruning, and enables to increase the conduction speed of the nerve impulse. In the human brain, its progression follows a different calendar in different bundles and varies across cerebral regions from the second part of pregnancy to the end of adolescence.

At the cellular scale, myelination relies on successive phenomena. The "premyelinating" state generally refers to the initial period when pre-oligodendroglial cells increase and settle along the axons (Baumann and Pham-Dinh 2001), and when the cholesterol and glycolipids concentration starts to increase (Barkovich, et al. 1988; Poduslo and Jang 1984). The following "true" myelination process corresponds to the ensheathment of oligodendroglial processes around axons, and to the chemical maturation of the myelin sheath with rising amount of macromolecules (Barkovich, et al. 1988; Poduslo and Jang 1984). At the microscopic scale, the myelination induces major modifications in water molecules' content and compartmentalization (Matsumae, et al. 2001), and in protein and lipid contents (Barkovich, et al. 1988; Kucharczyk, et al. 1994), leading to huge changes in MR images of the developing brain. Information about the myelination progression is now available in vivo with MR parameters that capture different mechanisms of maturation: T1 and T2 relaxation times (see chapters \#1, 297), DTI (see chapters \#15, 291, 296) and myelin-related parameters (see chapter \#15) (Dubois, et al. 2013).

\section{Regional asynchrony of white matter myelination}

Post mortem studies have detailed the myelination sequence (Brody, et al. 1987; Flechsig 1920; Gilles, et al. 1983; Kinney, et al. 1988; Yakovlev 1962; Yakovlev and Lecours 1967) (for reviews (Baumann and Pham-Dinh 2001; Dubois, et al. 2013). It follows a caudorostral gradient and progresses from the center of the brain to the periphery, occurring earlier and faster 1) in proximal pathways than in distal ones; 2) in sensory pathways (somatosensory, vision, audition) than in motor ones; 3 ) in projection fibres than in associative ones; 4) in central regions than in polar ones; 5) in the occipital pole than in the posterior parietal white matter and in the temporal and frontal poles. 
Mapping the asynchrony of maturation in healthy newborns and infants with MRI has demonstrated acute changes during the first postnatal year, less rapid modifications during toddlerhood, and slower changes thereafter until young adulthood (Dubois, et al. 2013). While there is early evidence of myelination in specific white matter regions before $28 \mathrm{w}$ GA (Counsell, et al. 2002), an abrupt increase in myelinated white matter is detected on T1w and T2w images in preterm newborns between 35 and 41w GA (Huppi, et al. 1998b). Early differences between several projection and association bundles are identified between 28 and 43w GA by DTI (Partridge, et al. 2004), and hold up between 4 and 18w of postnatal age as highlighted by modelling distinct maturational stages in infants (Dubois, et al. 2008a). The spatio-temporal pattern of myelination progression provided by the myelin water fraction between 3 months and 60 months is coherent with histological studies (Deoni, et al. 2012), and the maturational delays across white matter bundles can be deduced by computing maturational distances between infants and adults from T1, T2 and DTI parameters (Kulikova, et al. in revision) (Figure 6a). Within a single bundle, asynchronous fronts of maturation, relying on different pools of fibres, are even distinguished using tractography-based analyses, as demonstrated for the motor pathway and the somato-sensory radiations within the cortico-spinal tract of preterm newborns (Berman, et al. 2005) and for the thalamo-cortical fibres and corticothalamic fibres within the optic radiations of infants (Dubois, et al. 2008b).

\section{Functional correlates of white matter myelination}

Aside from the investigation of normal maturation through the modelling of time trajectories (see chapter \#314), in vivo longitudinal studies may provide early structural biomarkers of functional development. Fibre myelination leads to a spectacular increase in the conduction speed of the nerve impulse (Baumann and Pham-Dinh 2001), which was confirmed in infants for the developing visual system by correlating the optic radiations maturation, measured by DTI, and functional responses assessed with EEG (Dubois, et al. 2008b) (Figure 6b). Myelination is thus assumed to improve the functional efficiency of brain networks (van der Knaap, et al. 1991). As examples, expressive and receptive language abilities during toddlerhood are related to the myelin water fraction in the white matter underlying frontal and temporal cortices (O'Muircheartaigh, et al. 2014), and visuospatial working memory performance at one year of age correlates with microstructural characteristics of white matter tracts that connect involved brain regions (Short, et al. 2013).

However relationships between the structural and functional maturation of the connectivity networks are probably much more complex. First, instead of triggering the development of functional networks, myelination may rather depend on it, since neuronal maturation and electrical activity control myelination induction (Barres and Raff 1993; Demerens, et al. 1996; Gyllensten and Malmfors 1963; Kinney, et al. 1988; Tauber, et al. 1980). Second, myelination appears uncorrelated with functional maturation in some cerebral systems (e.g. the auditory system), and extending myelination beyond a given age may enable to maintain similar latencies between cerebral regions across ages by compensating for brain growth (Dubois, et al. 2013; Salami, et al. 2003). Conversely, oligodendrocytes and myelin may play an inhibitory role on neuritic growth, partly explaining the weak plasticity of the adult brain (Ng, et al. 1996). Finally, intracortical myelinated fibres are not well developed even at 6 years of age (Kostovic, et al. 2014).The functional maturation of structural connectivity, mediated by fibre myelination, and the role of experience-dependent mechanisms are still to be clarified in healthy infants in relation with the networks' critical periods. Then exploring the development of functional networks may be used as a complementary approach. 


\section{Development of the functional connectivity}

Resting-state networks have been mapped in the adult brain using multi-channel electroencephalography (see chapter \#7), near-infrared spectroscopy (see chapter \#16) or functional connectivity MRI (fcMRI), with the hypothesis that distant brain regions within a network demonstrate synchronized fluctuations in spontaneous neural activity (see chapters \#212, 213, 335,341 ). Since the first study of sedated preterm newborns at term-equivalent age (Fransson, et al. 2007), several groups have detailed the developing functional connectivity (Lubsen, et al. 2011; Smyser, et al. 2011), because this approach is easy to implement in babies during natural sleep.

\section{Evolution of functional connectivity: late preterm and post-term periods}

While it might be thought that resting-state networks emerge in parallel with the development of related cognitive functions mostly during the post-term period, they rather seem to settle during the third trimester of gestation. Between 19 to $39 \mathrm{w} \mathrm{GA}$, the fetal brain demonstrates in fcMRI an organization in modules that overlap functional systems observed postnatally (Thomason, et al. 2014). In preterm newborns from 26w GA, functional networks involve varied cortical regions, the thalamus and cerebellum (Doria, et al. 2010; Smyser, et al. 2010), and during the preterm period the connectome architecture strongly develops, the interhemispheric connectivity increases (van den Heuvel, et al. 2014), and the age-related patterns of development differ across networks (Doria, et al. 2010; Smyser, et al. 2010) (Figure 7a). By term age (40w GA), the full networks (visual, auditory, somatosensory, motor, frontoparietal and executive control networks) are observed (Doria, et al. 2010; Fransson, et al. 2009; van den Heuvel, et al. 2014), the architecture seems similar as the adult, nevertheless cortical hubs and associated networks may remain mostly confined to primary sensory-motor regions, suggesting that architecture is first linked to support tasks related to basal perception and action behavior (Fransson, et al. 2011). During the first postnatal year, the maturation sequence progresses differently across networks, from the primary sensorimotor/auditory networks, to the visual networks, to the default-mode network (highly similar between 2-year-old toddlers and adults (Gao, et al. 2009)), and finally to executive control networks (Gao, et al. 2014). In newborns, note that only high-amplitude EEG events show strong spatial correlations (Omidvarnia, et al. 2013).

\section{Origins of functional connectivity in the developing brain}

While resting-state activities in the immature and mature brains present quite similar patterns, the formers do not seem to be a precursor of the latters, since underlying mechanisms differ in terms of function and origin, particularly in primary sensory systems (Colonnese and Khazipov 2012): during the preterm period, the default state of cortical networks is "silence" in comparison with the continuous activity measured in the mature brain, and both endogenous and sensory-driven electrical activities are critical for wiring and refining the developing circuitry (Penn and Shatz 1999). The spontaneous thalamo-cortical activity in immature primary sensory regions is generated largely by the sensory periphery, whereas intrinsic activity in the adult brain is generated within cortical circuits (Colonnese and Khazipov 2012).

FcMRI, EEG and NIRS imaging modalities may further reflect different mechanisms underlying the development of functional connectivity. Functional connections related to highamplitude EEG events in newborns may provide the endogenous guidance for the early activitydependent development (Omidvarnia, et al. 2013), whereas the origins of long-range spatial correlations detected with fcMRI in preterm newborns are not well-understood yet, since the majority of long axonal pathways are still developing (Omidvarnia, et al. 2013). Nonetheless, functional connections may be partly related to structural connections, since a positive coupling between both connectivity measures is observed in preterm newborns at 30 and 40w GA (van 
den Heuvel, et al. 2014) (Figure 7b) and strengthen with age during childhood (Hagmann, et al. 2010). Because tractography demonstrates intrinsic technical limitations with fibre interruptions in the cortex, structural measures may reflect mono-synaptic connections, whereas functional measures may also include poly-synaptic connections (Smyser, et al. 2011).

\section{Conclusion}

During normal development, the setting up of brain connectivity is a complex process based on several intermingled mechanisms at the structural and functional levels. Even though recent histological and MRI studies have enabled to highlight part of these mechanisms, the story is just beginning notably to understand how this development may be impacted by genetic, epi-genetic and environmental factors, or early disturbances (e.g. in utero growth, preterm birth, hypoxic-ischaemic lesion, neonatal stroke, post-natal environment) (Ball, et al. 2014; FischiGomez, et al. 2014; Gao, et al. 2014; Grieve, et al. 2008; Smyser, et al. 2013). Despite challenges to study foetuses and infants, combining complementary post mortem and in vivo approaches should provide a great opportunity to investigate the developing brain at different scales, from microstructure to functional organisation.

\section{Acknowledgment}

The authors thank Goran Sedmak for help in preparation of diagrams (Figures 1-3). This work has been supported by Croatian Science Foundation Grant No. 09.01/414 (to M.J.). as well as grants (to J.D.) from the Fyssen Foundation, the "Fondation de France" and the European Union Seventh Framework Program (FP7/2007-2013, grant agreement n604102). 
Figure 1: Growing pathways during the early fetal period

During the early fetal period (here illustrated at $11 \mathrm{PCW}$ ), growing pathways are predominantly longitudinally oriented, involved in growth and pathfinding within the intermediate zone and establishing transient connections within the subplate.

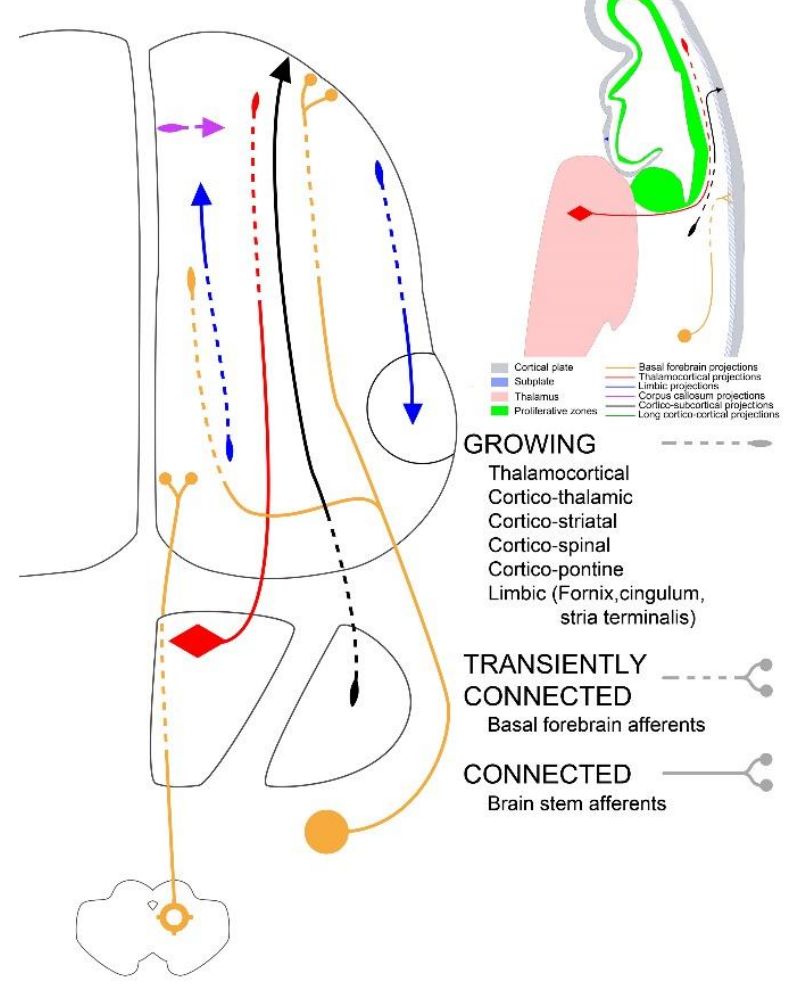


Figure 2: Growing pathways during the early preterm period

At the beginning of the early preterm period (24 PCW), the relocation of thalamocortical and basal forebrain afferent fibres from the subplate into the cortical plate begins, leads to initial synaptogenesis within the cortical plate and the establishment of the first permanent connectivity. Note the early growth of long and short medial (limbic) cortico-cortical connectivity and modular termination of efferent corticostriatal projections.

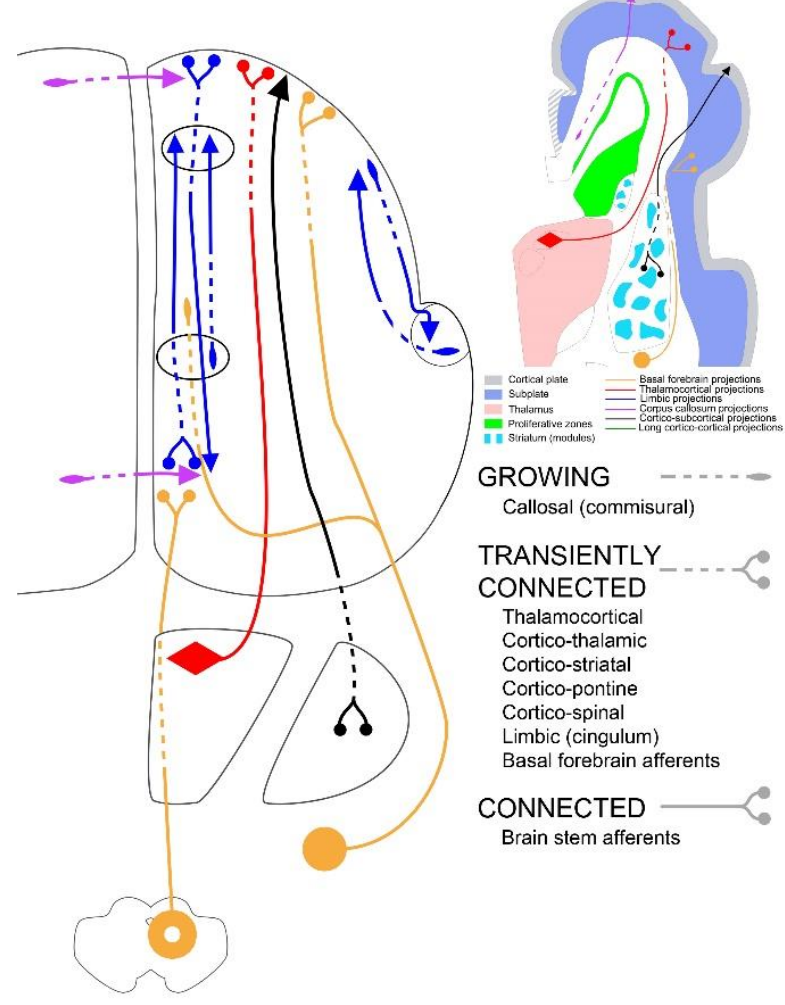


Figure 3: Growing pathways during the late preterm period

At the end of the early preterm period (28 PCW) and during the later preterm period (29-34 PCW), there is a rapid development of both afferent and efferent cortical connectivity in both longitudinal and transverse directions. Note that, although few neocortical associative pathways develop early (see text), most cortico-cortical long pathways are still growing and short corticocortical connections remain poorly developed.

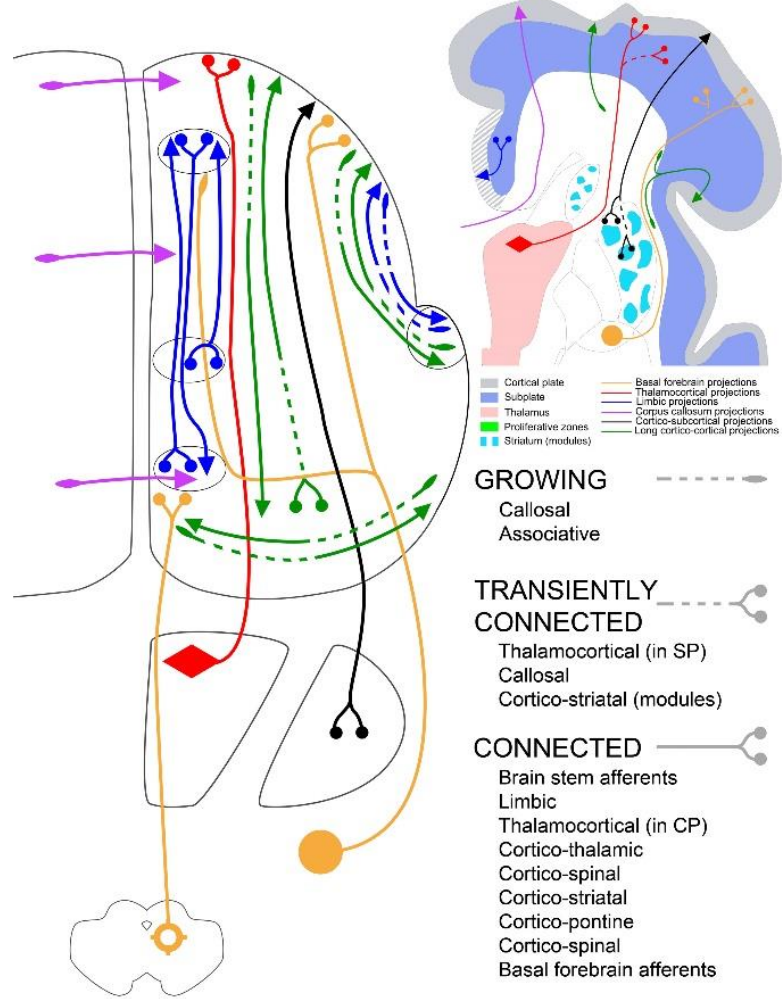


Figure 4: Pathways tractography in foetuses in utero

Sensorimotor and callosal trajectories at 24w GA (upper row), 26w GA, 31w GA and 35w GA (lower row). Reproduced with permission from (Kasprian, et al. 2008).

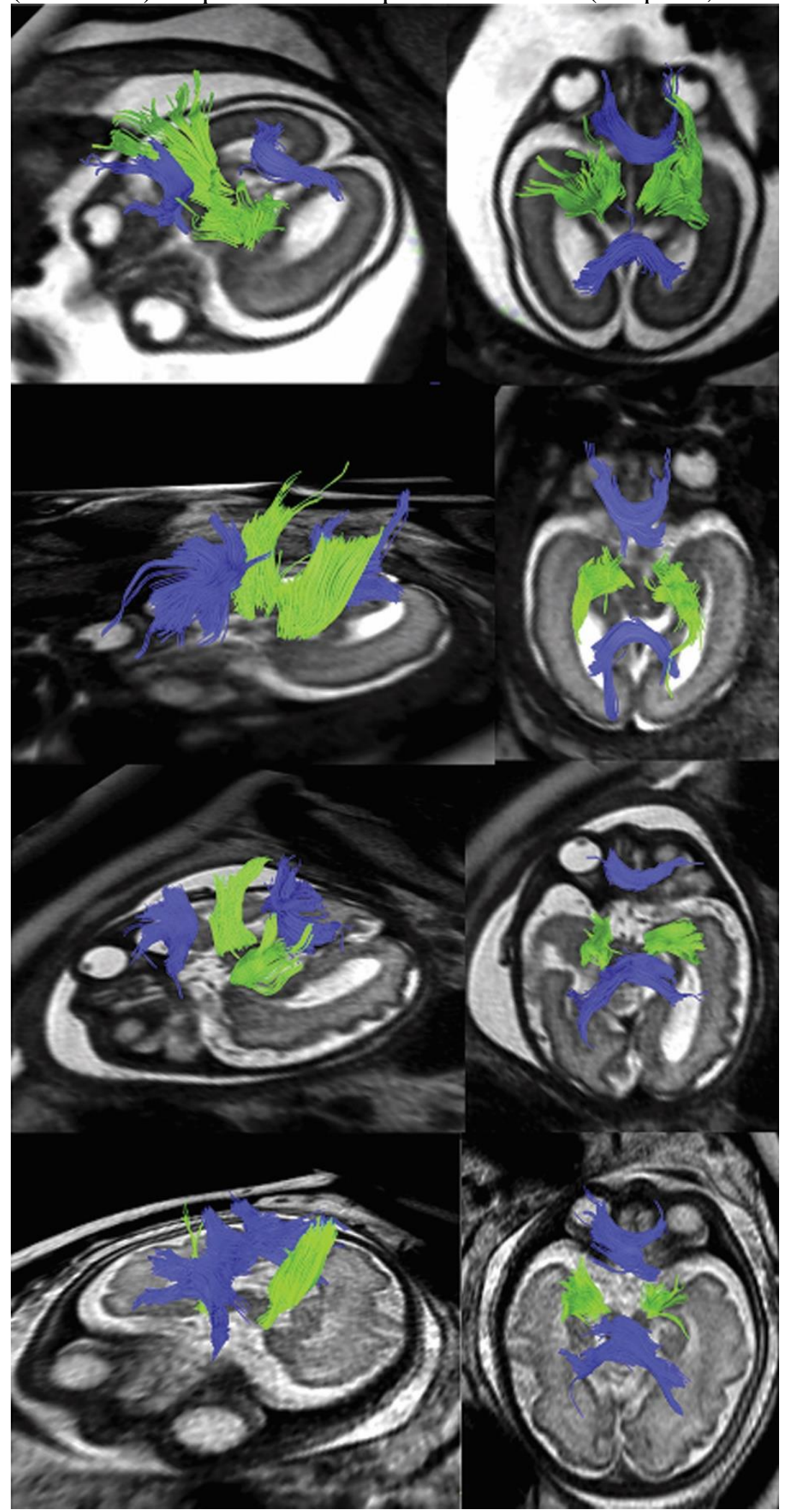




\section{Figure 5: Histological and imaging observations of the developing pathways}

Figure 5a: A-D: Development of afferent fibres at $11 \mathrm{PCW}$ revealed by AChE histochemical staining (A, C) and DTI (B, D). Red arrows point to the diencephalo-telencephalic junction, and curved arrow to the external capsule; DTI revelas thalamocortical fibres passing through the cerebral stalk (cs) originating from the dorsomedial thalamic complex. E-I: At 15 PCW, basal forebrain fibre bundles are running through the external capsule (E, curved arrow) and external sagittal stratum at $15 \mathrm{PCW}(\mathrm{F})$, while thalamocortical fibres are running through the internal sagittal stratum at $15 \mathrm{PCW}(\mathrm{G})$ and at $17 \mathrm{PCW}(\mathrm{H})$. The DTI also reveals cortico pontine fibre bundles at 15 PCW (I). Reproduced with permission from (Vasung, et al. 2010). Figure 5b: A-D: Development of associative pathways and crossroad formation during midfetal period. The formation of cingulum bundle (red colour) at $17 \mathrm{PCW}$ is shown by AChE staining (A) and DTI (B). At 15 PCW (B) and 17 PCW (C) the amygdala connections and crossroad C6 become more complex, as revealed by DTI (C). At 19 PCW, the crossroad C1 formation can be visualized by SNAP immunohistochemistry and DTI (D). Note that the crossroad C1 consists of axonal pathways running in radial (thalamocortical), saggital (associative) and transverse (callosal) direction. E: The development of associative fibre bundles revealed by DTI colour coded map (left), GNG staining (middle) and PAS staining (right). The prospective trajectories of the associative pathways are indicated by asterisks (left, middle) or outlined by colours (right). Reproduced with permission from (Vasung, et al. 2010).

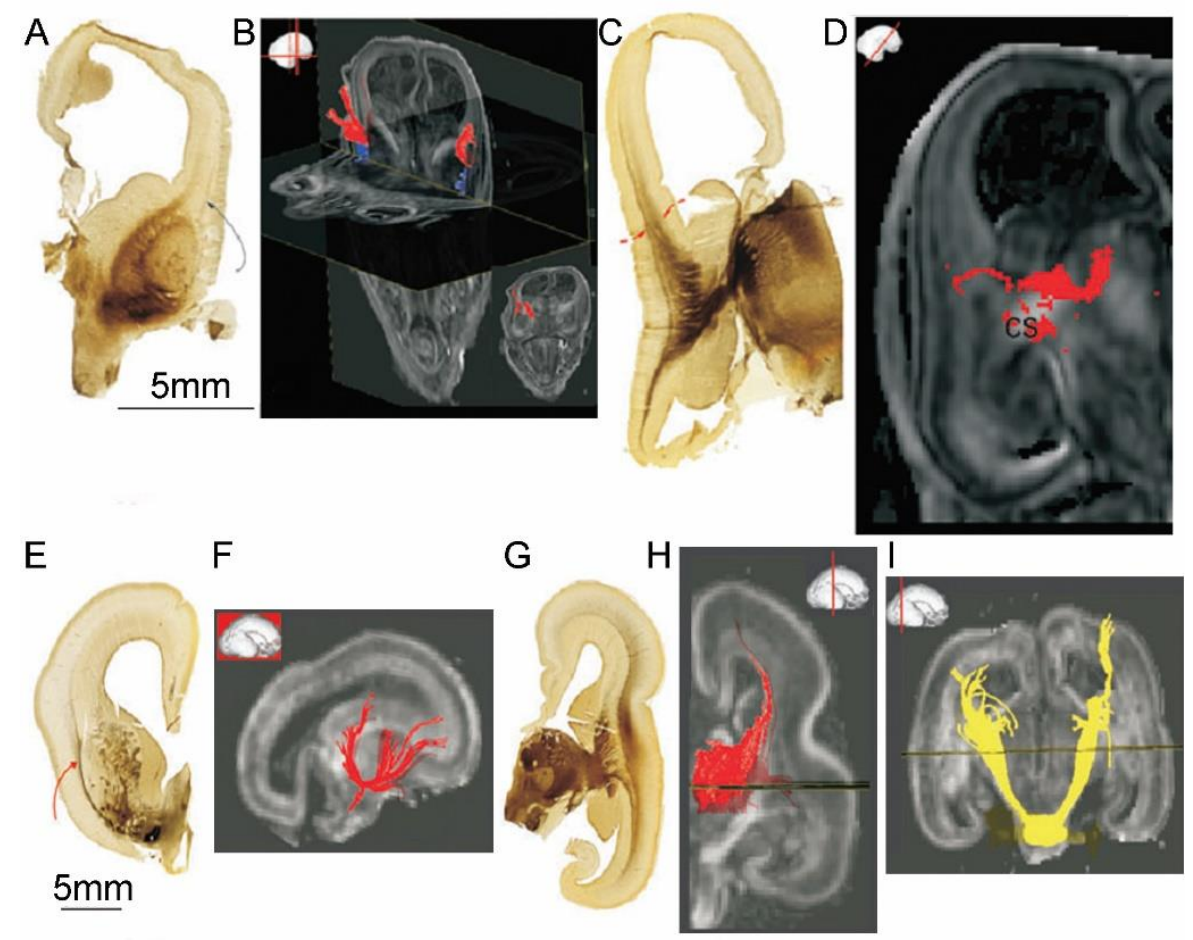




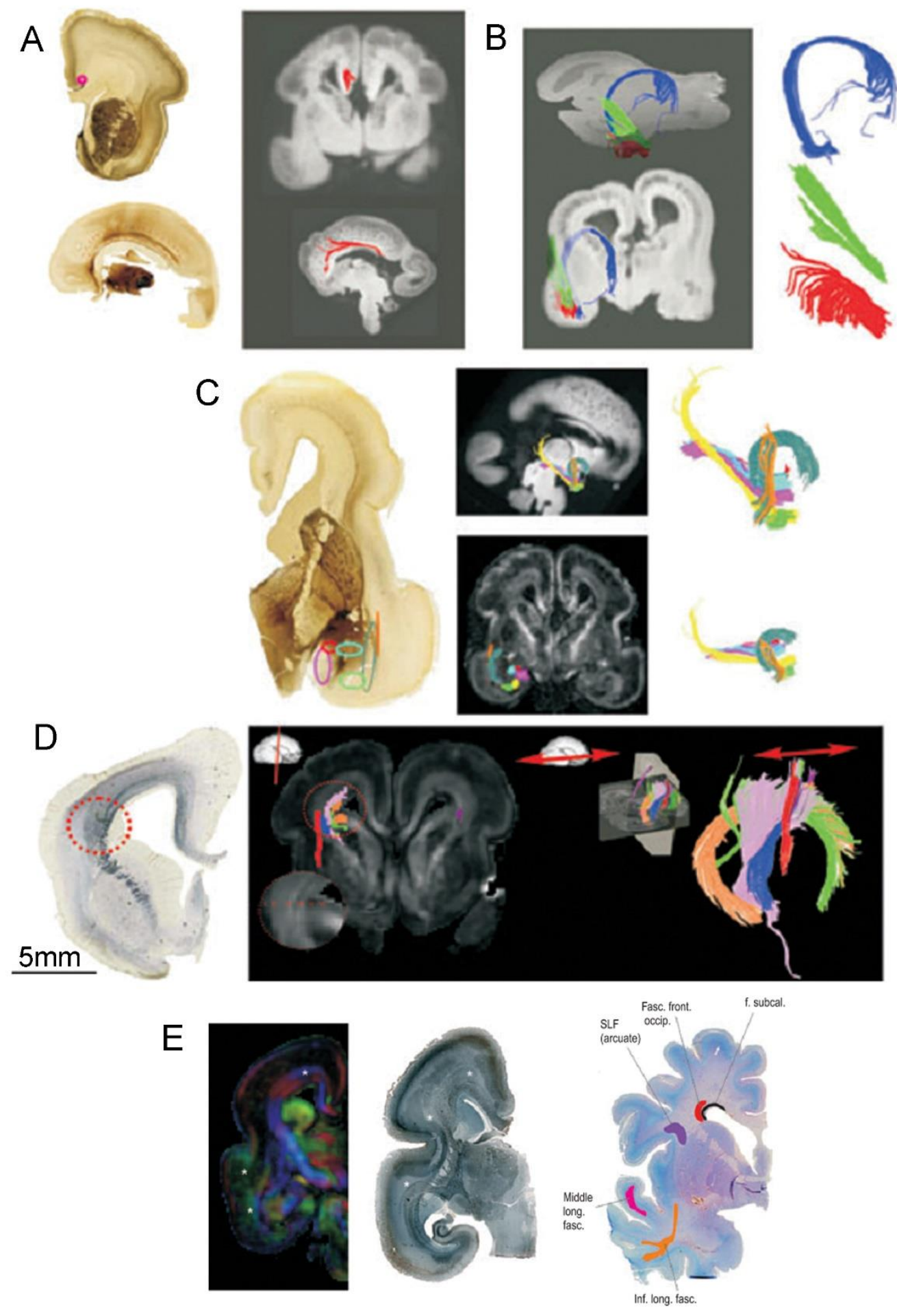




\section{Figure 6: Maturation of the structural networks}

a: The regional asynchrony in white matter maturation is highlighted in healthy infants using multi-parametric MRI. Projection, limbic, commissural and association bundles are ordered and coloured according to their maturation, and maturational delays (in weeks) are computed between pairs of bundles (Kulikova, et al. in revision).

Abbreviations: AF arcuate fasciculus; ALIC anterior limb of the internal capsule; CC corpus callosum (g/b/s genu/body/splenium): CG cingulum (inf/sup inferior/superior parts); CST cortico-spinal tract (inf/mid/sup inferior/middle/superior portions); EC external capsule; FX fornix; iFOF inferior fronto-occipital fasciculus; ILF inferior longitudinal fasciculus; OR optic radiations; SLF superior longitudinal fasciculus; STT spino-thalamic tract; UF uncinate fasciculus.

b: Correlations between the brain anatomical development and functional development are assessed for the visual system, whose maturation is intense during the first postnatal months. Cerebral responses are measured with EEG while the infant is looking at visual stimuli. The latency of the first positive peak (P1) of event-related potentials (ERPs) strongly decreases after birth, in relation with the increase in the nerve impulse conduction speed. Indeed, this speed (defined as the ratio between travelled distance and P1 latency) increases more with the optic radiations myelination (assessed by MRI-DTI) than with age in 1 to 4-month old infants (Dubois, et al. 2008b).

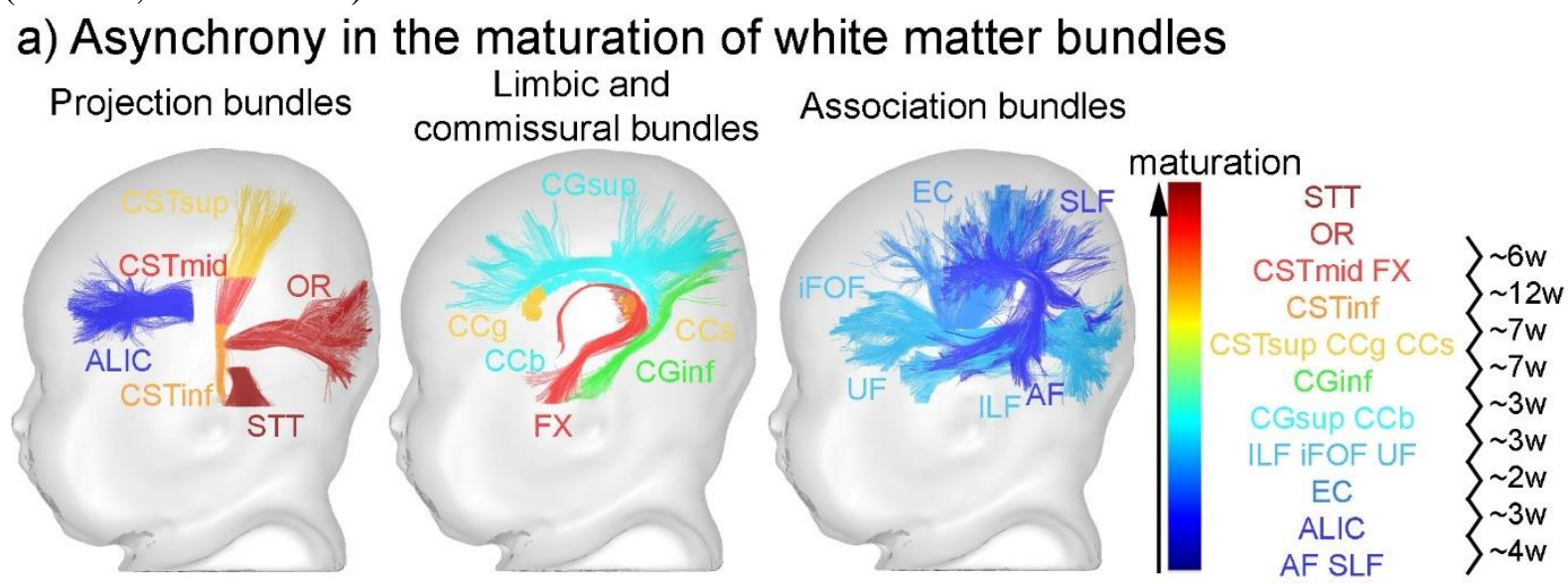

b) Anatomo-functional correlations for the developing visual system
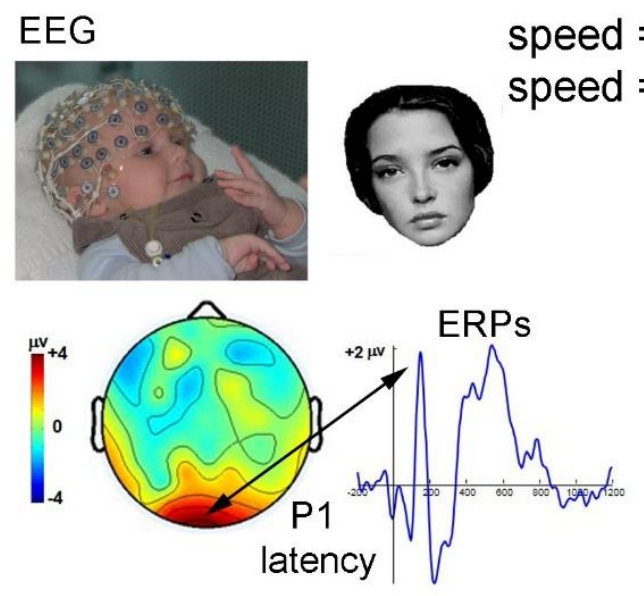

speed $=$ distance $/ \mathrm{P}_{1}$ latency speed $=\alpha \cdot \lambda_{\perp}+\beta$.age $+\gamma$

$\mathrm{R}^{2}=0.86$

DTI in the optic radiations

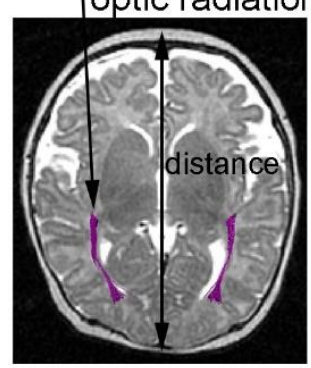

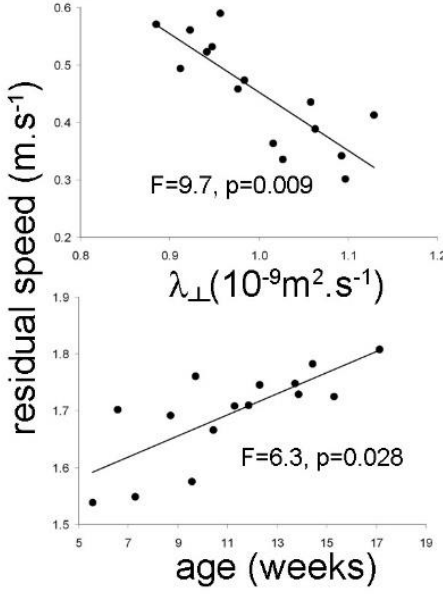


Figure 7: Development of functional networks

a: Functional networks are present early on in the developing brain and further strengthen during the preterm and post-term periods. As an example, the sensori-motor network is mapped with fcMRI in preterm newborns between $29 w$ and 41 w GA (upper row) and in infants during the first postnatal year (lower row). Reproduced with permission from (Doria, et al. 2010) and (Gao, et al. 2014).

b: In the neonatal brain, a structural basis of functional connectivity is suggested by the clear overlap between functional and structural connectivity matrices (over all pairs of brain regions) of preterm newborns at 30 and 40w GA. Four functional communities (in the temporal, occipital, central and frontal regions) are revealed based on functional connectivity, and levels of structural connectivity are computed according to the numbers of fibres reconstructed by tractography between regions. Reproduced with permission from (van den Heuvel, et al. 2014).

\section{a) Sensori-motor network identified by fcMRI in the developing brain}

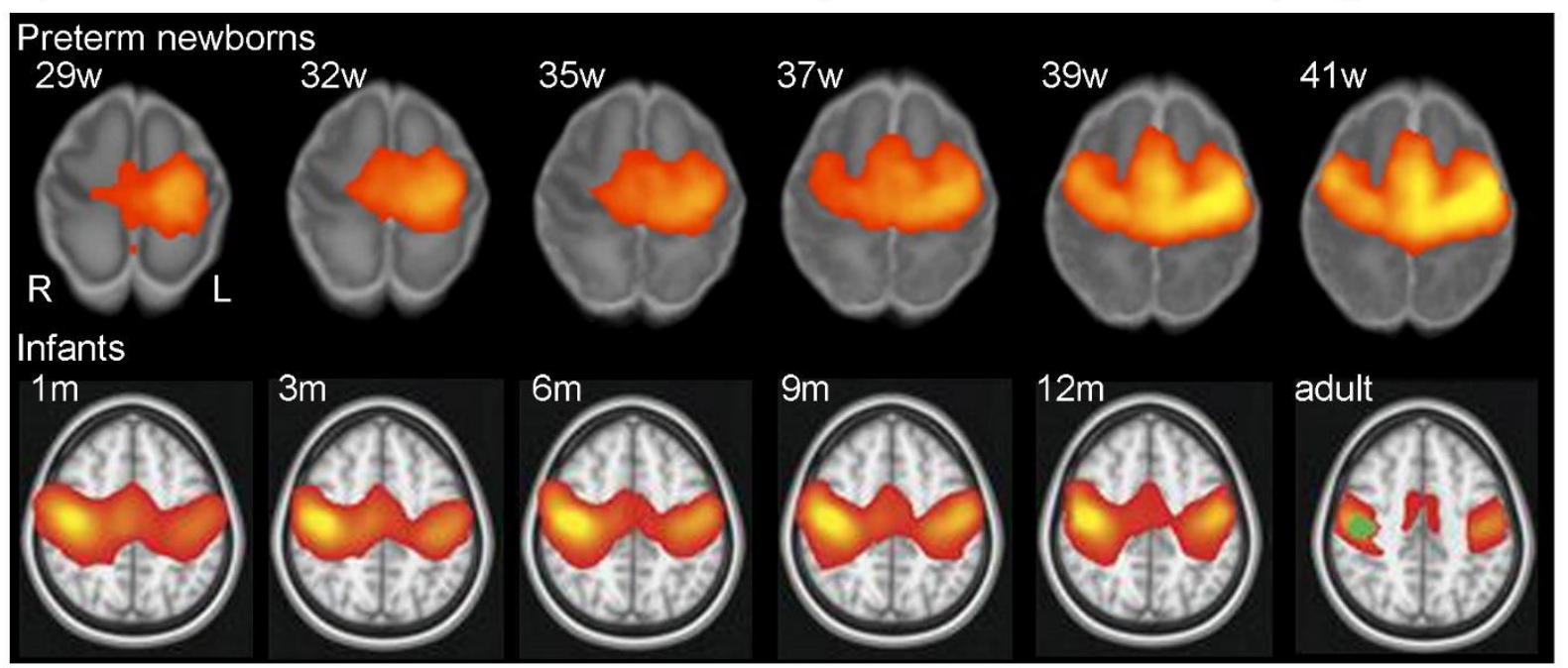

b) Functional and structural connectivity matrices in the neonatal brain
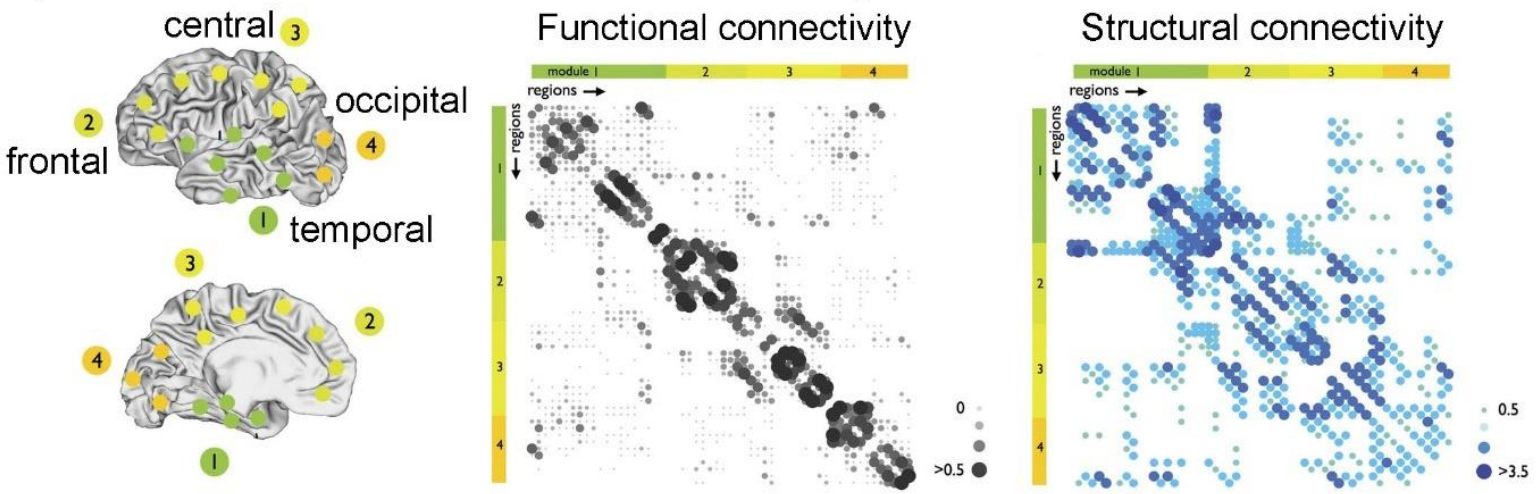


\section{References}

Ball G, Aljabar P, Zebari S, Tusor N, Arichi T, Merchant N, Robinson EC, Ogundipe E, Rueckert D, Edwards AD and others. 2014. Rich-club organization of the newborn human brain. Proc Natl Acad Sci U S A 111(20):7456-61.

Barkovich AJ, Kjos BO, Jackson DE, Jr., Norman D. 1988. Normal maturation of the neonatal and infant brain: MR imaging at $1.5 \mathrm{~T}$. Radiology 166(1 Pt 1):173-80.

Barres BA, Raff MC. 1993. Proliferation of oligodendrocyte precursor cells depends on electrical activity in axons. Nature 361(6409):258-60.

Baumann N, Pham-Dinh D. 2001. Biology of oligodendrocyte and myelin in the mammalian central nervous system. Physiol Rev 81(2):871-927.

Berger B, Alvarez C. 1994. Neurochemical development of the hippocampal region in the fetal rhesus monkey. II. Immunocytochemistry of peptides, calcium-binding proteins, DARPP-32, and monoamine innervation in the entorhinal cortex by the end of gestation. Hippocampus 4(1):85-114.

Berger B, Alvarez C, Goldman-Rakic PS. 1993. Neurochemical development of the hippocampal region in the fetal rhesus monkey. I. Early appearance of peptides, calcium-binding proteins, DARPP-32, and monoamine innervation in the entorhinal cortex during the first half of gestation (E47 to E90). Hippocampus 3(3):279-305.

Berman JI, Mukherjee P, Partridge SC, Miller SP, Ferriero DM, Barkovich AJ, Vigneron DB, Henry RG. 2005. Quantitative diffusion tensor MRI fiber tractography of sensorimotor white matter development in premature infants. Neuroimage 27(4):862-71.

Bourgeois JP, Goldman-Rakic PS, Rakic P. 1994. Synaptogenesis in the prefrontal cortex of rhesus monkeys. Cereb Cortex 4(1):78-96.

Brody BA, Kinney HC, Kloman AS, Gilles FH. 1987. Sequence of central nervous system myelination in human infancy. I. An autopsy study of myelination. J Neuropathol Exp Neurol 46(3):283-301.

Bui T, Daire JL, Chalard F, Zaccaria I, Alberti C, Elmaleh M, Garel C, Luton D, Blanc N, Sebag G. 2006. Microstructural development of human brain assessed in utero by diffusion tensor imaging. Pediatr Radiol 36(11):1133-40.

Burkhalter A. 1993. Development of forward and feedback connections between areas V1 and V2 of human visual cortex. Cereb Cortex 3(5):476-87.

Colonnese M, Khazipov R. 2012. Spontaneous activity in developing sensory circuits: Implications for resting state fMRI. Neuroimage 62(4):2212-21.

Corbett-Detig J, Habas PA, Scott JA, Kim K, Rajagopalan V, McQuillen PS, Barkovich AJ, Glenn OA, Studholme C. 2011. 3D global and regional patterns of human fetal subplate growth determined in utero. Brain Struct Funct 215(3-4):255-63.

Counsell SJ, Maalouf EF, Fletcher AM, Duggan P, Battin M, Lewis HJ, Herlihy AH, Edwards AD, Bydder GM, Rutherford MA. 2002. MR imaging assessment of myelination in the very preterm brain. AJNR Am J Neuroradiol 23(5):872-81.

Demerens C, Stankoff B, Logak M, Anglade P, Allinquant B, Couraud F, Zalc B, Lubetzki C. 1996. Induction of myelination in the central nervous system by electrical activity. Proc Natl Acad Sci U S A 93(18):988792.

Deoni SC, Dean DC, 3rd, O'Muircheartaigh J, Dirks H, Jerskey BA. 2012. Investigating white matter development in infancy and early childhood using myelin water faction and relaxation time mapping. Neuroimage 63(3):1038-53

Doria V, Beckmann CF, Arichi T, Merchant N, Groppo M, Turkheimer FE, Counsell SJ, Murgasova M, Aljabar $\mathrm{P}$, Nunes RG and others. 2010. Emergence of resting state networks in the preterm human brain. Proc Natl Acad Sci U S A 107(46):20015-20.

Dreyfuss-Brisac C. 1979. Ontogenesis of brain bioelectrical activity and sleep organization in neonates and infants. In: Falkner F, Tanner JM (Eds), Human Growth. Vol. 3. Neurobiology and Nutrition.(London: BailliereTindall):157-182.

Dubois J, Dehaene-Lambertz G, Kulikova S, Poupon C, Hüppi PS, Hertz-Pannier L. 2013. The early development of brain white matter: a review of imaging studies in fetuses, newborns and infants. Neuroscience DOI 10.1016/j.neuroscience.2013.12.044.

Dubois J, Dehaene-Lambertz G, Perrin M, Mangin JF, Cointepas Y, Duchesnay E, Le Bihan D, Hertz-Pannier L. 2008a. Asynchrony of the early maturation of white matter bundles in healthy infants: quantitative landmarks revealed noninvasively by diffusion tensor imaging. Hum Brain Mapp 29(1):14-27.

Dubois J, Dehaene-Lambertz G, Soares C, Cointepas Y, Le Bihan D, Hertz-Pannier L. 2008b. Microstructural correlates of infant functional development: example of the visual pathways. J Neurosci 28(8):1943-8.

Fischi-Gomez E, Vasung L, Meskaldji DE, Lazeyras F, Borradori-Tolsa C, Hagmann P, Barisnikov K, Thiran JP, Huppi PS. 2014. Structural Brain Connectivity in School-Age Preterm Infants Provides Evidence for Impaired Networks Relevant for Higher Order Cognitive Skills and Social Cognition. Cereb Cortex. 
Flechsig P. 1920. Anatomie des Menschlichen Gehirn und Rückenmarks, auf myelogenetischer grundlage G. Thieme.

Fransson P, Aden U, Blennow M, Lagercrantz H. 2011. The functional architecture of the infant brain as revealed by resting-state fMRI. Cereb Cortex 21(1):145-54.

Fransson P, Skiold B, Engstrom M, Hallberg B, Mosskin M, Aden U, Lagercrantz H, Blennow M. 2009. Spontaneous brain activity in the newborn brain during natural sleep--an fMRI study in infants born at full term. Pediatr Res 66(3):301-5.

Fransson P, Skiold B, Horsch S, Nordell A, Blennow M, Lagercrantz H, Aden U. 2007. Resting-state networks in the infant brain. Proc Natl Acad Sci U S A 104(39):15531-6.

Gao W, Alcauter S, Elton A, Hernandez-Castillo CR, Smith JK, Ramirez J, Lin W. 2014. Functional Network Development During the First Year: Relative Sequence and Socioeconomic Correlations. Cereb Cortex.

Gao W, Zhu H, Giovanello KS, Smith JK, Shen D, Gilmore JH, Lin W. 2009. Evidence on the emergence of the brain's default network from 2-week-old to 2-year-old healthy pediatric subjects. Proc Natl Acad Sci U S A 106(16):6790-5.

Gilles F, Shankle W, Dooling E. 1983. Myelinated tracts: growth patterns. Gilles F., Leviton A. and Dooling E. eds. John Wright PSG, Boston.

Goldman-Rakic PS. 1981. Prenatal formation of cortical input and development of cytoarchitectonic compartments in the neostriatum of the rhesus monkey. J Neurosci 1(7):721-35.

Graziani LJ, Katz L, Cracco Q, Cracco JB, Weitzman ED. 1974. The maturation and interrelationship of EEF patterns and auditory evoked response in premature infants. Electroencephalogr Clin Neurophysiol 36(4):367-75.

Grieve PG, Isler JR, Izraelit A, Peterson BS, Fifer WP, Myers MM, Stark RI. 2008. EEG functional connectivity in term age extremely low birth weight infants. Clin Neurophysiol 119(12):2712-20.

Gyllensten L, Malmfors T. 1963. Myelinization of the optic nerve and its dependence on visual function--a quantitative investigation in mice. J Embryol Exp Morphol 11:255-66.

Hagmann P, Sporns O, Madan N, Cammoun L, Pienaar R, Wedeen VJ, Meuli R, Thiran JP, Grant PE. 2010. White matter maturation reshapes structural connectivity in the late developing human brain. Proc Natl Acad Sci U S A 107(44):19067-72.

Hevner RF. 2000. Development of connections in the human visual system during fetal mid-gestation: a DiItracing study. J Neuropathol Exp Neurol 59(5):385-92.

Hevner RF, Kinney HC. 1996. Reciprocal entorhinal-hippocampal connections established by human fetal midgestation. J Comp Neurol 372(3):384-94.

Hrbek A, Karlberg P, Olsson T. 1973. Development of visual and somatosensory evoked responses in pre-term newborn infants. Electroencephalogr Clin Neurophysiol 34(3):225-32.

Huang H, Zhang J, Wakana S, Zhang W, Ren T, Richards LJ, Yarowsky P, Donohue P, Graham E, van Zijl PC and others. 2006. White and gray matter development in human fetal, newborn and pediatric brains. Neuroimage 33(1):27-38.

Huppi PS, Maier SE, Peled S, Zientara GP, Barnes PD, Jolesz FA, Volpe JJ. 1998a. Microstructural development of human newborn cerebral white matter assessed in vivo by diffusion tensor magnetic resonance imaging. Pediatr Res 44(4):584-90.

Huppi PS, Warfield S, Kikinis R, Barnes PD, Zientara GP, Jolesz FA, Tsuji MK, Volpe JJ. 1998b. Quantitative magnetic resonance imaging of brain development in premature and mature newborns. Ann Neurol 43(2):224-35.

Innocenti GM, Price DJ. 2005. Exuberance in the development of cortical networks. Nat Rev Neurosci 6(12):95565.

Judas M. 2011. Prenatal development of the human fetal telencephalon. In: Prayer D. (ed) Fetal MRI. Berlin: Springer:81-146.

Judas M, Rados M, Jovanov-Milosevic N, Hrabac P, Stern-Padovan R, Kostovic I. 2005. Structural, immunocytochemical, and $\mathrm{mr}$ imaging properties of periventricular crossroads of growing cortical pathways in preterm infants. AJNR Am J Neuroradiol 26(10):2671-84.

Judas M, Sedmak G, Pletikos M. 2010a. Early history of subplate and interstitial neurons: from Theodor Meynert (1867) to the discovery of the subplate zone (1974). J Anat 217(4):344-67.

Judas M, Sedmak G, Pletikos M, Jovanov-Milosevic N. 2010b. Populations of subplate and interstitial neurons in fetal and adult human telencephalon. J Anat 217(4):381-99.

Kasprian G, Brugger PC, Weber M, Krssak M, Krampl E, Herold C, Prayer D. 2008. In utero tractography of fetal white matter development. Neuroimage 43(2):213-24.

Kinney HC, Brody BA, Kloman AS, Gilles FH. 1988. Sequence of central nervous system myelination in human infancy. II. Patterns of myelination in autopsied infants. J Neuropathol Exp Neurol 47(3):217-34.

Kostovic I. 1986. Prenatal development of nucleus basalis complex and related fiber systems in man: a histochemical study. Neuroscience 17(4):1047-77. 
Kostovic I, Goldman-Rakic PS. 1983. Transient cholinesterase staining in the mediodorsal nucleus of the thalamus and its connections in the developing human and monkey brain. J Comp Neurol 219(4):431-47.

Kostovic I, Jovanov-Milosevic N, Rados M, Sedmak G, Benjak V, Kostovic-Srzentic M, Vasung L, Culjat M, Huppi P, Judas M. 2014. Perinatal and early postnatal reorganization of the subplate and related cellular compartments in the human cerebral wall as revealed by histological and MRI approaches. Brain Struct Funct 219(1):231-53.

Kostovic I, Judas M. 2002. Correlation between the sequential ingrowth of afferents and transient patterns of cortical lamination in preterm infants. Anat Rec 267(1):1-6.

Kostovic I, Judas M. 2006. Prolonged coexistence of transient and permanent circuitry elements in the developing cerebral cortex of fetuses and preterm infants. Dev Med Child Neurol 48(5):388-93.

Kostovic I, Judas M. 2007. Transient patterns of cortical lamination during prenatal life: do they have implications for treatment? Neurosci Biobehav Rev 31(8):1157-68.

Kostovic I, Judas M. 2010. The development of the subplate and thalamocortical connections in the human foetal brain. Acta Paediatr 99(8):1119-27.

Kostovic I, Judas M, Petanjek Z, Simic G. 1995. Ontogenesis of goal-directed behavior: anatomo-functional considerations. Int J Psychophysiol 19(2):85-102.

Kostovic I, Judas M, Rados M, Hrabac P. 2002. Laminar organization of the human fetal cerebrum revealed by histochemical markers and magnetic resonance imaging. Cereb Cortex 12(5):536-44.

Kostovic I, Krmpotic J. 1976. Early prenatal ontogenesis of the neuronal connections in the interhemispheric cortex of the human gyrus cinguli. Verh Anat Ges(70 Pt 1):305-16.

Kostovic I, Lukinovic N, Judas M, Bogdanovic N, Mrzljak L, Zecevic N, Kubat M. 1989. Structural basis of the developmental plasticity in the human cerebral cortex: the role of the transient subplate zone. Metab Brain Dis 4(1):17-23.

Kostovic I, Petanjek Z, Judas M. 1993. Early areal differentiation of the human cerebral cortex: entorhinal area. Hippocampus 3(4):447-58.

Kostovic I, Rakic P. 1984. Development of prestriate visual projections in the monkey and human fetal cerebrum revealed by transient cholinesterase staining. J Neurosci 4(1):25-42.

Kostovic I, Rakic P. 1990. Developmental history of the transient subplate zone in the visual and somatosensory cortex of the macaque monkey and human brain. J Comp Neurol 297(3):441-70.

Kostovic I, Vasung L. 2009. Insights from in vitro fetal magnetic resonance imaging of cerebral development. Semin Perinatol 33(4):220-33.

Krmpotic-Nemanic J, Kostovic I, Kelovic Z, Nemanic D. 1980. Development of acetylcholinesterase (AChE) staining in human fetal auditory cortex. Acta Otolaryngol 89(3-4):388-92.

Krmpotic-Nemanic J, Kostovic I, Kelovic Z, Nemanic D, Mrzljak L. 1983. Development of the human fetal auditory cortex: growth of afferent fibres. Acta Anat (Basel) 116(1):69-73.

Kucharczyk W, Macdonald PM, Stanisz GJ, Henkelman RM. 1994. Relaxivity and magnetization transfer of white matter lipids at MR imaging: importance of cerebrosides and pH. Radiology 192(2):521-9.

Kulikova S, Hertz-Pannier L, Dehaene-Lambertz G, Poupon C, Dubois J. in revision. Multi-parametric Evaluation of the White Matter Maturation. Brain Struct Funct.

LaMantia AS, Rakic P. 1990. Axon overproduction and elimination in the corpus callosum of the developing rhesus monkey. J Neurosci 10(7):2156-75.

Lubsen J, Vohr B, Myers E, Hampson M, Lacadie C, Schneider KC, Katz KH, Constable RT, Ment LR. 2011. Microstructural and functional connectivity in the developing preterm brain. Semin Perinatol 35(1):3443.

Maas LC, Mukherjee P, Carballido-Gamio J, Veeraraghavan S, Miller SP, Partridge SC, Henry RG, Barkovich AJ, Vigneron DB. 2004. Early laminar organization of the human cerebrum demonstrated with diffusion tensor imaging in extremely premature infants. Neuroimage 22(3):1134-40.

Mahmoudzadeh M, Dehaene-Lambertz G, Fournier M, Kongolo G, Goudjil S, Dubois J, Grebe R, Wallois F. 2013. Syllabic discrimination in premature human infants prior to complete formation of cortical layers. Proc Natl Acad Sci U S A 110(12):4846-51.

Marin-Padilla M. 1978. Dual origin of the mammalian neocortex and evolution of the cortical plate. Anat Embryol (Berl) 152(2):109-26.

Matsumae M, Kurita D, Atsumi H, Haida M, Sato O, Tsugane R. 2001. Sequential changes in MR water proton relaxation time detect the process of rat brain myelination during maturation. Mech Ageing Dev 122(12):1281-91.

Meyer G, Schaaps JP, Moreau L, Goffinet AM. 2000. Embryonic and early fetal development of the human neocortex. J Neurosci 20(5):1858-68.

Milh M, Kaminska A, Huon C, Lapillonne A, Ben-Ari Y, Khazipov R. 2007. Rapid cortical oscillations and early motor activity in premature human neonate. Cereb Cortex 17(7):1582-94. 
Molliver ME, Kostovic I, van der Loos H. 1973. The development of synapses in cerebral cortex of the human fetus. Brain Res 50(2):403-7.

Ng WP, Cartel N, Roder J, Roach A, Lozano A. 1996. Human central nervous system myelin inhibits neurite outgrowth. Brain Res 720(1-2):17-24.

Nobin A, Bjorklund A. 1973. Topography of the monoamine neuron systems in the human brain as revealed in fetuses. Acta Physiol Scand Suppl 388:1-40.

Novak GP, Kurtzberg D, Kreuzer JA, Vaughan HG, Jr. 1989. Cortical responses to speech sounds and their formants in normal infants: maturational sequence and spatiotemporal analysis. Electroencephalogr Clin Neurophysiol 73(4):295-305.

O'Muircheartaigh J, Dean DC, 3rd, Ginestet CE, Walker L, Waskiewicz N, Lehman K, Dirks H, Piryatinsky I, Deoni SC. 2014. White matter development and early cognition in babies and toddlers. Hum Brain Mapp 35(9):4475-4487.

Olson L, Boreus LO, Seiger A. 1973. Histochemical demonstration and mapping of 5-hydroxytryptamine- and catecholamine-containing neuron systems in the human fetal brain. Z Anat Entwicklungsgesch 139(3):259-82.

Omidvarnia A, Fransson P, Metsaranta M, Vanhatalo S. 2013. Functional Bimodality in the Brain Networks of Preterm and Term Human Newborns. Cereb Cortex.

Partridge SC, Mukherjee P, Henry RG, Miller SP, Berman JI, Jin H, Lu Y, Glenn OA, Ferriero DM, Barkovich AJ and others. 2004. Diffusion tensor imaging: serial quantitation of white matter tract maturity in premature newborns. Neuroimage 22(3):1302-14.

Penn AA, Shatz CJ. 1999. Brain waves and brain wiring: the role of endogenous and sensory-driven neural activity in development. Pediatr Res 45(4 Pt 1):447-58.

Petanjek Z, Judas M, Simic G, Rasin MR, Uylings HB, Rakic P, Kostovic I. 2011. Extraordinary neoteny of synaptic spines in the human prefrontal cortex. Proc Natl Acad Sci U S A 108(32):13281-6.

Poduslo SE, Jang Y. 1984. Myelin development in infant brain. Neurochem Res 9(11):1615-26.

Rakic P, Bourgeois JP, Goldman-Rakic PS. 1994. Synaptic development of the cerebral cortex: implications for learning, memory, and mental illness. Prog Brain Res 102:227-43.

Salami M, Itami C, Tsumoto T, Kimura F. 2003. Change of conduction velocity by regional myelination yields constant latency irrespective of distance between thalamus and cortex. Proc Natl Acad Sci U S A 100(10):6174-9.

Schwartz ML, Goldman-Rakic PS. 1991. Prenatal specification of callosal connections in rhesus monkey. J Comp Neurol 307(1):144-62.

Scott JA, Habas PA, Kim K, Rajagopalan V, Hamzelou KS, Corbett-Detig JM, Barkovich AJ, Glenn OA, Studholme C. 2011. Growth trajectories of the human fetal brain tissues estimated from 3D reconstructed in utero MRI. Int J Dev Neurosci 29(5):529-36.

Short SJ, Elison JT, Goldman BD, Styner M, Gu H, Connelly M, Maltbie E, Woolson S, Lin W, Gerig G and others. 2013. Associations between white matter microstructure and infants' working memory. Neuroimage 64:156-66.

Slater R, Cantarella A, Gallella S, Worley A, Boyd S, Meek J, Fitzgerald M. 2006. Cortical pain responses in human infants. J Neurosci 26(14):3662-6.

Smyser CD, Inder TE, Shimony JS, Hill JE, Degnan AJ, Snyder AZ, Neil JJ. 2010. Longitudinal analysis of neural network development in preterm infants. Cereb Cortex 20(12):2852-62.

Smyser CD, Snyder AZ, Neil JJ. 2011. Functional connectivity MRI in infants: exploration of the functional organization of the developing brain. Neuroimage 56(3):1437-52.

Smyser CD, Snyder AZ, Shimony JS, Blazey TM, Inder TE, Neil JJ. 2013. Effects of white matter injury on resting state fMRI measures in prematurely born infants. PLoS One 8(7):e68098.

Takahashi E, Folkerth RD, Galaburda AM, Grant PE. 2012. Emerging cerebral connectivity in the human fetal brain: an MR tractography study. Cereb Cortex 22(2):455-64.

Tauber H, Waehneldt TV, Neuhoff V. 1980. Myelination in rabbit optic nerves is accelerated by artificial eye opening. Neurosci Lett 16(3):235-8.

Thomason ME, Brown JA, Dassanayake MT, Shastri R, Marusak HA, Hernandez-Andrade E, Yeo L, Mody S, Berman S, Hassan SS and others. 2014. Intrinsic functional brain architecture derived from graph theoretical analysis in the human fetus. PLoS One 9(5):e94423.

van den Heuvel MP, Kersbergen KJ, de Reus MA, Keunen K, Kahn RS, Groenendaal F, de Vries LS, Benders MJ. 2014. The Neonatal Connectome During Preterm Brain Development. Cereb Cortex.

Van der Knaap MS, Valk J. 1995a. Myelin and white matter. Magnetic resonance of myelin, myelination and myelin disorders, Van der Knaap MS and Valk J eds, Springer-Verlag, Berlin:1-17.

Van der Knaap MS, Valk J. 1995b. Myelination and retarded myelination. Magnetic resonance of myelin, myelination and myelin disorders, Van der Knaap MS and Valk J eds, Springer-Verlag, Berlin. 
van der Knaap MS, Valk J, Bakker CJ, Schooneveld M, Faber JA, Willemse J, Gooskens RH. 1991. Myelination as an expression of the functional maturity of the brain. Dev Med Child Neurol 33(10):849-57.

Vanhatalo S, Palva JM, Andersson S, Rivera C, Voipio J, Kaila K. 2005. Slow endogenous activity transients and developmental expression of $\mathrm{K}+\mathrm{Cl}-$ cotransporter 2 in the immature human cortex. Eur J Neurosci 22(11):2799-804.

Vasung L, Huang H, Jovanov-Milosevic N, Pletikos M, Mori S, Kostovic I. 2010. Development of axonal pathways in the human fetal fronto-limbic brain: histochemical characterization and diffusion tensor imaging. J Anat 217(4):400-17.

Verney C. 1999. Distribution of the catecholaminergic neurons in the central nervous system of human embryos and fetuses. Microsc Res Tech 46(1):24-47.

Verney C, Lebrand C, Gaspar P. 2002. Changing distribution of monoaminergic markers in the developing human cerebral cortex with special emphasis on the serotonin transporter. Anat Rec 267(2):87-93.

Volpe JJ. 2008. Neuronal Proliferation, Migration, Organization, and Myelination. Neurology of the Newborn. Saunders, Elsevier, Inc, Philadelphia.:51-118.

Von Monakow C. 1905. Gehirnpathologie. Wien: Alfred Holder.

Yakovlev PI. 1962. Morphological criteria of growth and maturation of the nervous system in man. Res Publ Assoc Res Nerv Ment Dis 39:3-46.

Yakovlev PI, Lecours AR. 1967. The myelogenetic cycles of regional maturation in the brain. In: Regional development of the brain in early life Minowski A. eds, Blackwell, Oxford:3-69.

Zecevic N, Verney C. 1995. Development of the catecholamine neurons in human embryos and fetuses, with special emphasis on the innervation of the cerebral cortex. J Comp Neurol 351(4):509-35. 